\title{
Study on Prediction Model of Tourist Amount of Scenic Spot Based on BP Neural Network Algorithm
}

\author{
Liu Yongqiu \\ Guangdong University of Science \& Technology, Dongguan, Guangdong, 523083, China
}

Keywords: Neural network algorithm, Mount Tai Scenic Spot, Tourist amount

\begin{abstract}
In recent years, the expansion of tourism market has put forward new requirements to strengthen the management of scenic spots, in this paper, it takes Mount Tai Scenic Area as the researching object, establishing the prediction model of tourist amount by using BP neural network algorithm, so as to predict the amount of tourists of scenic spots. Through the experimental result, we can know that the algorithm of this model is fast and effective. Therefore, it can verify the possibility of using neural network algorithm to predict tourist amount in the scenic spots.
\end{abstract}

\section{Introduction}

With the extensive application of artificial intelligence algorithm, BP neural network algorithm as well as its similar learning algorithm can realize its advantages gradually compared with the original static algorithm. BP algorithm is a kind reverse supervised learning algorithm, its main idea is as follows: inputting learning samples, adjusting and training network weights and deviation repeatedly by using back-propagation algorithm, so as to make the output vector and expected vector be as close as possible, when the sum of error square of network's output layer is less than the specified error, the train is complete, then it can save the network weights and deviation. This algorithm has a good effect in the field of artificial intelligence prediction. In recent years, Mount Tai Scenic Spot has been regarded as the World Cultural and Natural Heritage by the UNESCO, world geological park, national 5A scenic spot in China, national scenic spot, national key cultural relics protection unit, China's intangible cultural heritage. The total number of tourists entering this scenic spot is increasing year by year. Due to the difference of the tourist season of the different places, as well as weather and cultural factors and so on, during the hot season, the number of climbing Mount Tai can reach to about 0.2 million people, the least number is only a few thousand people, because the visiting number is extremely unbalanced, it can result in the frequent management problems of scenic spot ${ }^{[1-3]}$.

The purpose of this study is to take Mount Tai Scenic Spot as sample, using BP neural network algorithm to establish the prediction model of Mount Tai Scenic Spot, so as to improve the ability of service department of Mount Tai Scenic Spot on the development of scenic spots as well as tourists' management.

\section{Prediction Method of BP Network}

BP neural network processing unit is the nonlinear input and output relationship, the connection weights of each layer can be adjusted by the learning regulation, the information of network can pass from the topology feed forward transfer of previous layer unit to all the nodes of the next corresponding layer ${ }^{[4]}$. The state of the neurons in each layer can only affect the state of the neurons of the next layer. In addition to the nodes of the input layer, the net 
input of the hidden layer and the output layer node is the weighted sum of the outputs of the previous layer nodes ${ }^{[5]}$.

BP algorithm is a kind of more mature and guided training method, which is a unidirectional propagation of multilayer feed forward network. Input signal can pass from the input node, followed by the hidden layer nodes, and then to the output node, the output of each layer node can only affect the input of the next layer nodes. The formula of calculating actual output is as follows, Formula 1

$$
y_{j}=f\left(\sum W_{j i} x_{i}\right)
$$

Among them, function $f()$ is generally Sigmoid function, which can be shown in Formula 2

$$
f(x)=\frac{1}{1+e^{-x}}
$$

Adjusting the weights, according to the direction of the error backpropagation, from the output node, so as to return to the hidden layer to correct the weights according to Formula 3:

$$
W_{i j}(k+1)=W_{i j}(k)+\alpha\left[W_{i j}(k)-W_{i j}(k-1)\right]
$$

Training objective is to minimize the error function $E$, which can be shown in Formula (4)

$$
E=\frac{1}{2} \sum \sum\left(y_{j p}-t_{j p}\right)^{2}=\sum E_{p}
$$

(4) In the formula, $E$ is the network output error, $P$ represents the $P^{\text {th }}$ sample, $j$ is the number of output unit, $t_{j p}$ is the expected output of unit, while $y_{j p}$ is the actual output of unit.

If Formula (5) is introduced in Formula (3).

$$
h(x)=\sqrt{e} \frac{A}{R} x e^{\frac{-x^{2}}{R^{2}}}
$$

Then Formula (3) can be transferred, Formula (6).

$$
W_{i j}(k+1)=W_{i j}(k)+\alpha\left[W_{i j}(k)-W_{i j}(k-1)\right]+h(x)
$$

Among them, $\mathrm{A}$ and $\mathrm{R}$ can be regarded as the amplitude and the radius of the nonlinear self feedback. They can control the range of weights. When $\mathrm{R}$ is fixed, A can determine the range of the transferred dynamic power of the dynamical system of the weights between the space when the energy is partially extremely less, the greater A is, the wider the range of weight correction is. This formula is a chaotic mechanism. Introducing it to Formula (7):

$$
x=\Delta w_{i j}(k)=w_{i j}(k)-w_{i j}(k-1)
$$

Assuming $|x|=\left|w_{i j}(k)-w_{i j}(k-1)\right|$ can indicate the speed that dynamic system is close to the fixed point, if $|x|$ is very large then it can indicate that the system is far away from the fixed point, $h(x)$ should be quickly reduced, so that the correction of the weight can approach to the fixed point if the system quickly according to the direction of the gradient information. When $|x|$ is in the state of the middle value, the dynamic system of weights will enter a certain neighborhood of one certain fixed point, the self-feedback function of $h(x)$ feedback will produce new driving force and jump out of the fixed point, in the end, the weight can enter one certain neighborhood of the optimal fixed point under the global sense.

\section{BP Network Simulation}

It can adopt BP network of chaotic system that contains only one hidden layer to predict and analyze the trend of tourist amount of Mount Tai Scenic Spot, among them, the input layer can be including three neurons, the hidden layer can be including ten neurons, the output can be including one neuron, the weight value of network and threshold value can be randomly selected. Three variables of inputting can be selected for the following three months, while the output of the variables can be the corresponding tourist amount of Mount Tai Scenic 
Spot of the middle month of the input variables. Among them, the input parameters can be treated as follows: each month will be divided by the next month, the basic data can be shown in Table 1. The simulation curve can be shown in Figure 1.

Table 1 The Amount of Tourists in Mount Tai Scenic Spot from January, 2010 to December, 2015 (unit: 0.01 million people )

\begin{tabular}{|c|c|c|c|c|c|c|c|c|}
\hline $\begin{array}{l}\text { Serial } \\
\text { number }\end{array}$ & Month & $\begin{array}{c}\text { The } \\
\text { amount } \\
\text { of people }\end{array}$ & $\begin{array}{c}\text { Serial } \\
\text { number }\end{array}$ & Month & $\begin{array}{c}\text { The } \\
\text { amount of } \\
\text { people }\end{array}$ & $\begin{array}{c}\text { Serial } \\
\text { number }\end{array}$ & Month & $\begin{array}{c}\text { The } \\
\text { amount of } \\
\text { people }\end{array}$ \\
\hline 1 & 201001 & 98 & 25 & 201201 & 94 & 49 & 201401 & 87 \\
\hline 2 & 201002 & 36 & 26 & 201202 & 43 & 50 & 201402 & 39 \\
\hline 3 & 201003 & 46 & 27 & 201203 & 57 & 51 & 201403 & 65 \\
\hline 4 & 201004 & 101 & 28 & 201204 & 104 & 52 & 201404 & 109 \\
\hline 5 & 201005 & 194 & 29 & 201205 & 231 & 53 & 201405 & 265 \\
\hline 6 & 201006 & 165 & 30 & 201206 & 168 & 54 & 201406 & 205 \\
\hline 7 & 201007 & 146 & 31 & 201207 & 157 & 55 & 201407 & 195 \\
\hline 8 & 201008 & 131 & 32 & 201208 & 187 & 56 & 201408 & 176 \\
\hline 9 & 201009 & 99 & 33 & 201209 & 121 & 57 & 201409 & 187 \\
\hline 10 & 201010 & 179 & 34 & 201210 & 203 & 58 & 201410 & 251 \\
\hline 11 & 201011 & 87 & 35 & 201211 & 105 & 59 & 201411 & 96 \\
\hline 12 & 201012 & 62 & 36 & 201212 & 75 & 60 & 201412 & 56 \\
\hline 13 & 201101 & 102 & 37 & 201301 & 90 & 61 & 201501 & 88 \\
\hline 14 & 201102 & 44 & 38 & 201302 & 42 & 62 & 201502 & 49 \\
\hline 15 & 201103 & 52 & 39 & 201303 & 55 & 63 & 201503 & 87 \\
\hline 16 & 201104 & 128 & 40 & 201304 & 134 & 64 & 201504 & 189 \\
\hline 17 & 201105 & 221 & 41 & 201305 & 247 & 65 & 201505 & 295 \\
\hline 18 & 201106 & 187 & 42 & 201306 & 199 & 66 & 201506 & 221 \\
\hline 19 & 201107 & 166 & 43 & 201307 & 201 & 67 & 201507 & 196 \\
\hline 20 & 201108 & 162 & 44 & 201308 & 197 & 68 & 201508 & 168 \\
\hline 21 & 201109 & 103 & 45 & 201309 & 153 & 69 & 201509 & 99 \\
\hline 22 & 201110 & 197 & 46 & 201310 & 256 & 70 & 201510 & 243 \\
\hline 23 & 201111 & 86 & 47 & 201311 & 73 & 71 & 201511 & 115 \\
\hline 24 & 201112 & 57 & 48 & 201312 & 55 & 72 & 201512 & 61 \\
\hline
\end{tabular}

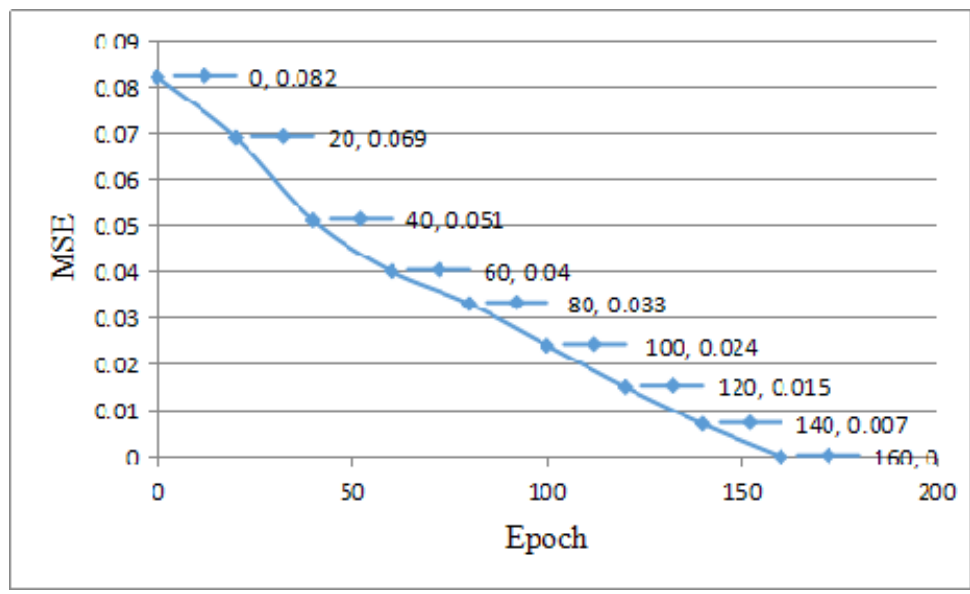

Fig. 1 Training Target Curve of BP Algorithm 
Having prediction on tourist amount of Mount Tai Scenic Spot from January, 2016 to March, 2016 by adopting BP network, it can get the tourist amount of Mount Tai Scenic Spot which are as follows: 0.963 million people, 0.525 million people, 1.025 million people, while the actual tourist amount in January, February and March of 2016 are as follows: 0.97 million people, 0.51 million people, 1.00 million people, which can prove that the prediction accuracy of BP network.

\section{Conclusion}

BP neural network has the advantages of simple structure, strong learning ability and high prediction accuracy, which is especially suitable for complex nonlinear system. Based on chaotic system, BP neural network can have the study on the prediction of tourists amount, the experiment shows us that this kind of algorithm can achieve the desired requirement, people can believe that with the improvement of the continuous increase of computer processing speed as well as the expansion of the other related technology, neural network technology will get further development and perfection, the result of this prediction model shows that the prediction of BP neural network algorithm on the tourist amount is accurate and reliable, and its application in the prediction of tourism will continue to become mature.

\section{Reference}

[1] Gong J, Xia W, Fu Y F, et al. A Review on the Cashew Nut Shelling Techniques[J]. Journal of Applied Science and Engineering Innovation, 2016, 3(4): 133-138.

[2] Lin C J, Chen H F, Lee T S. Forecasting tourism demand using time series, artificial neural networks and multivariate adaptive regression splines: evidence from Taiwan[J]. International Journal of Business Administration, 2011, 2(2): 14.

[3] Jiang Y, Qi J, Bai X. An Improved Neural Network Observer designed for nonlinear system[J]. Journal of applied science and engineering innovation Vol, 2014, 1(6): 376-383.

[4] Maia A L S, de Carvalho F A T. Holt's exponential smoothing and neural network models for forecasting interval-valued time series[J]. International Journal of Forecasting, 2011, 27(3): 740-759.

[5] Xueyan C, Shouchuang S. Application of Improved Wavelet Neural Network in Fault Diagnosis[J]. Journal of Applied Science and Engineering Innovation, 2015, 2(5): 146-149. 